\title{
KAEDAH PENGURUSAN HARTA WAKAF OLEH MAJLIS AGAMA ISLAM NEGERI KEDAH (MAIK): PELAKSANAAN PAJAKAN UNTUK 99 TAHUN
}

\author{
AZIZAN ABDUL RAHMAN \\ HYDZULKIFLI HASHIM OMAR \\ MOHD SOLLEHUDIN SHUIB \\ Pusat Pengajian Perniagaan Islam \\ Universiti Utara Malaysia
}

\begin{abstract}
Abstrak
Artikel ini membincangkan tentang kaedah pengurusan harta wakaf yang dilaksanakan Oleh Majlis Agama Islam Kedah (MAIK). Terdapat pelbagai kaedah pembangunan yang telah digunakan oleh MAIK untuk tujuan pengurusan yang optimal antaranya kaedah sewaan, istibdal, B.O.T (Build Operate Transfer), Pajakan 99 tahun, RMK-9 (Rancangan Malaysia Ke9) dan juga kaedah usahasama. Kajian ini memfokuskan kaedah pajakan 99 tahun yang telah diamalkan oleh MAIK untuk menguruskan harta wakaf yang berada dibawah seliaannya. Perbahasan dari segi figh juga diutarakan dalam kajian ini yang berkisar tentang kaedah pajakan tanah untuk tempoh 99 tahun. Hasil perbincangan ini kelak akan membolehkan institusi wakaf dinegeri lain menjadikan ianya sebagai acuan dalam usaha memartabatkan kelestarian harta wakaf yang diselia.
\end{abstract}

Kata kunci: Pengurusan Harta Wakaf, Pajakan 99 tahun, Majlis Agama Islam Kedah (MAIK)

\begin{abstract}
Purpose -To review the waqf management in the district of KubangPasu, Kedah. This research provided in terms of the development of waqf property by Majlis Agama Islam Kedah (MAIK). This research focused on the development of 99 year lease method that was successfully implemented.

Methodology - This study employed two methods; document analysis and also field research. Document analysis was used to study the development of waqf property and the management of assets in terms of leasing for 99 years. The information was collected from books, conference papers, and
\end{abstract}


journal articles. This study employed field research, where interviews were conducted with respondents that have good knowledge in this area such as the officer of waqf mutawalli in MAIK and also the project manager for the development of 99 year lease.

Findings -This study found that waqf management had been developed over time. Many methods were used to develop idle waqf land in Kedah. This study also discussed some of the fuqaha views in term of using the 99 year lease. It was found that leasing for 99 years can be used to successfully develop idle waqf land. It was also shown that MAIK had used this method to develop lands in Kedah.

Originality / Value - The findings of this study is very important for other Majlis Agama Islam Negeri to create some guidelines that can strengthen the waqf land management all over Malaysia.

Keywords - Waqf management, Least for 99 years, Majlis Agama Islam Kedah (MAIK)

\section{Pengenalan}

Ibn Abidin (2011) mendefinisikan harta adalah suatu perkara yang menjadi kecenderungan tabiat manusia untuk memilikinya serta boleh disimpan sehingga tempoh waktu seseorang itu memerlukannya. Harta merupakan setiap fizikal yang mempunyai nilai material pada pandangan manusia. Hashim dan Ab. Rahman (2013) menjelaskan harta adalah sesuatu yang boleh dimiliki dan diperdagangkan sekiranya sesuatu yang tidak boleh diperdagangkan maka dikira sebagai bukan harta.

Abu Zahrah (2009) menjelaskan maksud wakaf dari segi bahasa ialah tertahan (الحبس) dan (الهنع) menegah. Wakaf menurut istilah syarak ialah menahan sesuatu fizikal yang diwakafkan dari sebarang transaksi manakala manfaat yang diperoleh daripada sumber fizikal harta tersebut adalah diagihkan untuk tujuan kebajikan. Sementara, wakaf menurut definisi Enakmen Pentadbiran Undang-Undang Islam (Kedah Darul Aman) 2008 ialah:

"Apa-apa harta yang boleh dinikmati manfaat atau faedahnya untuk apa-apa tujuan khairat samada sebagai wakaf am atau wakaf khas menurut hukum Syarak".

(Warta Kerajaan 2008, ms. 174). 
al-Zarqa (1999) menyatakan hak terbahagi kepada dua kategori, iaitu dari aspek al-mal (harta) dan juga ghair al-mal (bukan harta). Perkataan al-mal ialah segala perkara yang berkaitan dengan harta seperti pemilikan suatu fizikal, hutang dan juga manfaat. Sementara pengunaan kalimah ghair al-mal pula merujuk kepada hak individu yang bukan berbentuk harta, seperti penjaga bertindak sebagai pengurus dalam memberikan pelajaran dan pendidikan kepada anakanak mereka selain daripada memberikan nafkah yang berbentuk kewangan. al-Zarqa (1999) mendefinisikan hak sebagai pengkhususan yang dibenarkan oleh syarak sebagai kuasa dan bebanan (taklif). Sementara, wakaf dari sudut istilah adalah bermaksud menahan fizikal harta daripada kepemilikan dan manfaat yang diperoleh daripada harta tersebut digunakan bagi tujuan kebajikan.

Manual Pengurusan Tanah Wakaf (2009) menjelaskan tentang hakhak dalam keseluruhan atau sebahagian tanah beri milik yang terletak hak pada penerima pindahan di dalam Seksyen 416C sebagai:

(1) Jika sekiranya keseluruhan atau sebahagian mana-mana tanah beri milik yang dipegang oleh pemindah diduduki, digunakan, dikawal atau diuruskan oleh penerima pindahan di bawah apa-apa hak atau kelayakan (entilement) yang diperolehi dengan cara derma (donation), hadiah (gift), warisan (bequest), kebenaran (consent), atau apa cara yang lain, dari pemindah atau mana-mana pendahulu dalam hakmilik pemindah untuk apa-apa maksud statutory penerima pindahan sebelum sahaja peletakhakan statutory berkuatkuasa, hak penerima pindahan kepada pendudukan, penggunaan, kawalan atau pengurusan tersebut hendaklah, atas pemohonan secara bertulis olehnya kepada pendaftar, diendorskan atas dokumen hakmilik daftaran kepada tanah. Jika pendaftar berpuas hati bahawa peletakhakan statutory tentang hak atau kelayakan tersebut pada penerima pindahan telah dikuatkuasakan.

(2) Hak yang diendorskan di atas dokumen hakmilik daftaran di bawah subseksyen (1) hendaklah berkuatkuasa dan akan kekal pada seluruh tempoh hakmilik itu dan hendaklah mengikat setiap tuan punya tanah yang kemudian".

Menurut al-Zarqa (1999) harta yang diwakafkan dikira sebagai sebuah harta wakaf setelah selesai akad penyerahan harta tersebut (iaitu bermula dari tarikh pendaftaran harta tersebut dibuat). Dari sudut hukum syarak, pemegang amanah terhadap harta wakaf 
boleh membuat tuntutan hak sekiranya berlaku pencerobohan dan rampasan ke atas sesebuah harta yang telah diwakafkan. Pemegang amanah juga diberikan kebenaran untuk membuat penjualan harta wakaf sebagai istibdal sekiranya melihat mana-mana harta wakaf yang kurang berpotensi untuk dimajukan atau tidak mendatangkan sebarang manfaat kepada umat Islam. Justeru, sebagai pemegang amanah harta wakaf, beliau mestilah terlebih dahulu memohon untuk mendapatkan persetujuan dan kebenaran daripada pihak mahkamah syariah.

Menurut Hydzulkifli Hashim Omar dan Asmak Ab. Rahman (2015), terdapat dua perkara paling asas yang perlu ada untuk melaksanakan ibadah yang mulia ini. Pertama menahan serta menjaga asset wakaf tersebut daripada rosak dan hilang (tahbis al-'asl). Keduanya, menyalur serta membuat pengagihan manfaat wakaf tersebut kepada penerima wakaf (tasbil al-thamarah).

\section{Hak-hak yang diakui dalam pengurusan harta wakaf}

Hak serta tanggungjawab Majlis Agama Islam Negeri (MAIN) bukan sekadar menjadi penerima harta daripada pewakaf (al-waqif) sahaja. Akan tetapi peranan yang dimainkan MAIN termasuklah sebagai pemegang hak dan tanggungjawab untuk membangun harta wakaf agar tidak menjadi harta yang tidak produktif. Hashim dan Ab. Rahman (2013), Umar (2003), al-Zarqa (1999) dan Kahf (1998) menjelaskan bahawa terdapat dua cara untuk membangunkan harta wakaf sama ada dengan menggunakan kaedah klasik atau kaedah moden. Di antara kaedah klasik yang diutarakan seperti al-hukr1(الحكر), al-istisna'2(الإنجارتان) al-ijaratani3 (الإستصناع), al-istibdal

$1 \quad$ Al-Hukr adalah akad sewa yang melibatkan jangka masa yang lama. Sementara kadar sewaan harta wakaf akan dibayar kepada pihak pengurusan wakaf secara beransur-ansur sehingga tamat tempoh.

2 Al-Istisna' adalah suatu akad yang dilakukan di antara pengurus wakaf dengan mana-mana institusi untuk membiayai sesebuah projek pembangunan di atas harta wakaf. Setelah projek pembangunan tersebut siap maka pembayaran akan dilakukan mengikut proses perjanjian yang telah dipersetujui bersama.

3 Al-Ijaratani adalah transaksi akad yang berlaku apabila pemegang amanah harta wakaf memberi kebenaran kepada pihak yang dipercayai serta mempunyai sumber kewangan yang kukuh untuk membangunkan sesebuah harta wakaf yang terpilih. Setelah projek pembangunan tersebut siap, maka pengurus wakaf akan menyewakan bangunan tersebut kepada pihak berkenaan sehingga selesai bayarannya samada melalui tempoh masa yang panjang atau pendek.

4 Al-Istibdal bermaksud membeli atau menukar sesuatu harta wakaf dengan harta yang lain yang lebih baik dan berpontensi sebagai gantian kepada harta wakaf dengan menurut hukum Syarak. Tujuannya adalah untuk mengekalkan harta wakaf agar manfaat dan pahala kebajikan sentiasa berterusan kepada pewakaf. 


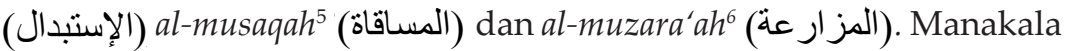
pembangunan secara moden adalah dengan menggunakan instrumen kewangan Islam kontemporari dan kaedah pembiayaan moden seperti build, operate and transfer (B.O.T). al-Zarqa (1999) menegaskan para fuqaha' terkemudian telah membincang beberapa jenis hak yang terdapat dalam harta wakaf adalah seperti berikut hak al-hukr, hak al-ijarataini, al-murshad dan juga hak al-kadik. Kesemua jenis hak yang diutarakan diperjelaskan seperti berikut:

\section{Hak al-hukr}

Hak al-hukr adalah akuan hak yang terkandung dalam harta wakaf melalui akad tempoh pajakan yang lama dengan persetujuan daripada kedua pihak yang bertranskasi. Melalui kaedah al-hukr pemajak harta wakaf mestilah membuat pembayaran dengan kadar yang segera. Nilai kadar yang perlu dibayar adalah hampir menyamai dengan kadar nilai tanah tersebut mengikut syarat dan terma yang dipersetujui secara bersama. Hak manafaat terhadap tanah wakaf tersebut akan beralih kepada penerima pajakan sehingga tamat tempoh perjanjian. Penerima pajakan mempunyai hak ke atas harta wakaf yang boleh mendatangkan hasil serta manfaat seperti tujuan pembinaan bangunan sama ada pejabat atau perumahan.

Hak yang terkandung di dalam kaedah al-hukr adalah pemajak mempunyai hak untuk melakukan transaksi sama ada melalui jualbeli dan juga harta ini boleh berpindah hak kepada pewaris sekiranya pemajak meninggal dunia. Akad al-hukr pula bertujuan untuk memproduktifkan harta wakaf yang kurang produktif.

\section{Hak al-ijarataini}

Hak al-ijarataini muncul pada zaman kerajaan Uthmaniah, iaitu sekitar tahun $1020 \mathrm{H}$ setelah berlaku tragedi kebakaran yang dahsyat di kota Constantinople. Kebanyakan yang terlibat adalah harta wakaf dan kos untuk memulih harta wakaf yang terbakar memerlukan kepada kos

5 Al-Musaqah adalah usahasama dalam pengurusan agro pertanian. Ianya melibatkan kontrak penyerahan pertanian kepada orang yang sanggup menjaga, mengairi serta membajai tanaman manakala gajinya akan dibayar oleh pihak pengurusan berdasarkan kepada perolehan hasil tanaman tersebut.

6 Al-Muzara'ah adalah pemilik harta menyerahkan harta pertanian yang tiada mempunyai sebarang tanaman kepada pengusaha supaya menjalankan urusan pertanian. Manakala keuntungan yang bakal diperolehi akan dibahagikan mengikut terma dan syarat yang telah dipersetujui bersama. 
yang besar. Rentetan daripada tragedi itu, para fuqaha' pada zaman kerajaan Uthmaniah berpandangan (ijtihad) harus membangun dan membaikpulih harta wakaf yang mengalami kerosakan yang teruk dengan menggunakan kaedah al-ijarataini.

Akad ijarataini merupakan suatu tempoh sewaan yang panjang setelah mendapat keizinan daripada pihak mahkamah syariah. Ini kerana pemegang amanah wakaf tidak mempunyai kemampuan untuk membangun harta wakaf yang terbengkalai atau mengalami kerosakan yang teruk. Pembayaran dalam akad al-ijarataini akan dilakukan dengan kadar segera, iaitu dengan mengikut nilai pembangunan tersebut. Manakala pembayaran secara penangguhan dilakukan pada setiap tahun, iaitu pada setiap kali akad diperbaharui. Dinamakan kaedah al-ijarataini adalah kerana harta wakaf tidak harus dijual dan pajakan juga tidak harus dilakukan dengan tempoh yang terlalu lama.

Perbezaan antara akad al-hukr dengan kaedah al-ijarataini adalah dalam akad al-hukr bangunan menjadi hak milik penerima pajakan kerana hasil yang diperoleh itu adalah modal sepenuhnya daripada penerima pajakan. Manakala dalam kaedah al-ijarataini bangunan dan tanah adalah masih kekal hak milik wakaf. Sekiranya pemegang amanah tidak mampu untuk menyiapkan projek yang terbengkalai maka projek tersebut terpaksa dipajak kepada pemaju untuk disiapkan. Pemaju bersetuju untuk membayar nilai pajakan secara segera mengikut nilai harta tersebut dan pembayaran secara tahunan dilakukan setiap kali pembaharuan akad dilakukan. Pemaju hanya mempunyai hak selama tempoh dalam perjanjian tersebut kemudian setelah tamat tempoh hak akan diserahkan kepada pemegang amanah.

\section{Hak al-Murshod}

Hak al-murshod iaitu hak mengawasi dan meninjau. Penjelasan kepada maksud hak al-murshod ialah pewakaf berhak melakukan peninjauan terhadap perjalanan pengurusan harta wakaf agar pelaksanaan harta wakaf bertetapan dengan hukum syarak.

\section{Hak al-Kadik}

Al-Kadik bermaksud penyewa yang menyewa kedai-kedai untuk tujuan perniagaan atau perindustrian. Kadang-kadang perniagaan memerlukan asas-asas utama seperti rak barang, dapur dan 
sebagainya. Sementara maksud al-Kadik adalah sesuatu yang sabit dan wujud di dalam kedai-kedai wakaf ketika perjanjian dilakukan. Penyewa boleh membuat penambahan (renoviation) melalui sumber kewangannya sendiri terhadap harta wakaf dengan syarat mestilah mendapat kebenaran daripada pemegang amanah wakaf.

Penyewa juga mempunyai akuan hak ke atas harta wakaf tersebut meskipun penyewa telah keluar dari kedai wakaf tersebut untuk diberikan sewa kepada pihak penyewa yang lain. Pembayaran sewaan akan dibahagikan kepada dua, iaitu pembayaran kepada pemegang amanah dan pembayaran kepada pemegang akuan sewa.

\section{Rukun Terhadap Harta Wakaf}

Rukun merupakan tulang belakang dalam melaksanakan sesuatu ibadah. Tidak kira ia berbentuk fardhu atau sunat. Begitu juga dengan rukun untuk tujuan berwakaf, ia terbahagi kepada beberapa bahagian, iaitu:

i) Pewakaf (al-waqif)

ii) Harta yang diwakafkan (al-mawquf)

iii) Penerima manfaat wakaf (al-mawquf'alaih)

iv) Pemberian dan penerimaan (al-sighah).

\section{Pewakaf}

Pewakaf (al-waqif) adalah individu yang mempunyai kelayakan untuk berwakaf dengan hartanya bagi tujuan kebajikan. Sementara syarat yang telah ditetapkan dalam rukun al-taklifi pula terdiri daripada baligh, berakal dan merdeka.

Berhubung dengan perkara tersebut Rasulullah S.A.W bersabda:

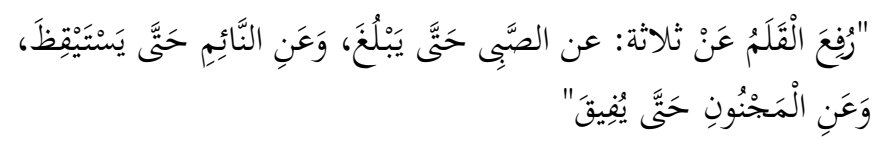

Diangkat pena dari catatan seseorang dalam tiga keadaan iaitu: kanak-kanak sehingga dia baligh, orang tidur sehingga dia terjaga dan orang yang gila sehingga sembuh (dari penyakit gilanya itu)"

(H.R Ahmad, al-Darimi, Abu Daud) 
IJMS 23 (1), 73-89 (2016)

\section{Harta yang diwakafkan (al-mawquf)}

Harta yang diwakafkan mestilah suatu yang mempunyai nilai pada pandangan orang ramai. Ibn Abidin (2011), menegaskan bahawa para fuqaha' menyatakan harta yang diharuskan berwakaf adalah sesuatu yang dibenarkan oleh syarak untuk mengambil manfaat dan faedah daripadanya.

Manual Pengurusan Harta Wakaf (2009) menjelaskan harta yang diwakafkan mestilah fizikal yang boleh dipindah milik dan harta itu mestilah hak kepunyaan pewakaf. Harta yang ingin diwakafkan dikira sah sekiranya mematuhi kriteria-kriteria seperti berikut iaitu:

i) Wakaf hendaklah dibuat secara kekal tanpa dihadkan untuk mana-mana tempoh tertentu.

ii) Wakaf khas, tujuan dan maksud wakaf hendaklah dinyatakan dengan jelas. Tidak sah wakaf jika tidak dinyatakan tujuan dan maksudnya.

iii) Harta yang telah diwakafkan berkuatkuasa serta merta, tidak boleh ditarik balik, tidak boleh diubah-ubah tujuannya dan tidak boleh tertakluk kepada syarat-syarat lain sebaliknya, kecuali melalui wakaf istibdal.

\section{Penerima manfaat wakaf (mawquf'alaih)}

Terdapat beberapa ketegori mawquf 'alaih antaranya adalah fakir miskin, musafir dan mereka yang layak menerimanya menurut pandangan hukum figh. Menurut Ibn Abidin (2011), ahlu al-Zimmah yang berada di bawah naungan kerajaan Islam juga layak menerima benifisiari daripada pembangunan harta wakaf sama seperti mereka yang layak menerima zakat fitrah.

\section{Sighah wakaf (ijab \& qabul)}

Pelaksanaan wakaf dianggap sah sekiranya wujud perkataan ijab dan qabul secara jelas (soreh) di antara dua pihak. Transaksi sighah melibatkan tawaran (ijab) dan pernyataan penerimaan (qabul) ketika proses itu berlangsung. Contohnya si Ahmad berkata: hartaku adalah sedekah untuk pembinaan masjid atau perkuburan dan seumpamanya. Dalam situasi yang sedemikian maka wakaf dikira sebagai sah dari segi hukum figh dan undang-undang.

7 Ahlu al-zimmah adalah mereka yang membayar jizyah dan mempunyai kontrak sosial yang bersifat berterusan dengan umat Islam serta sanggup bernaung di bawah negara dan hukum Islam (al-Mimmi, 1998). 


\section{Pandangan para fuqaha' terhadap pembangunan harta wakaf MAIK melalui pajakan (tempoh 99 tahun)}

Menurut Bahagian Wakaf MAIK, terdapat beberapa kaedah yang telah dilaksanakan bagi melestarikan pembangunan harta wakaf di negeri Kedah. Antara kaedah yang dilaksanakan sewa, istibdal, RMK9, B.O.T, pajakan dan usahasama. Ringkasan daripada pembangunan harta wakaf oleh MAIK adalah seperti didalam rajah 4.1.

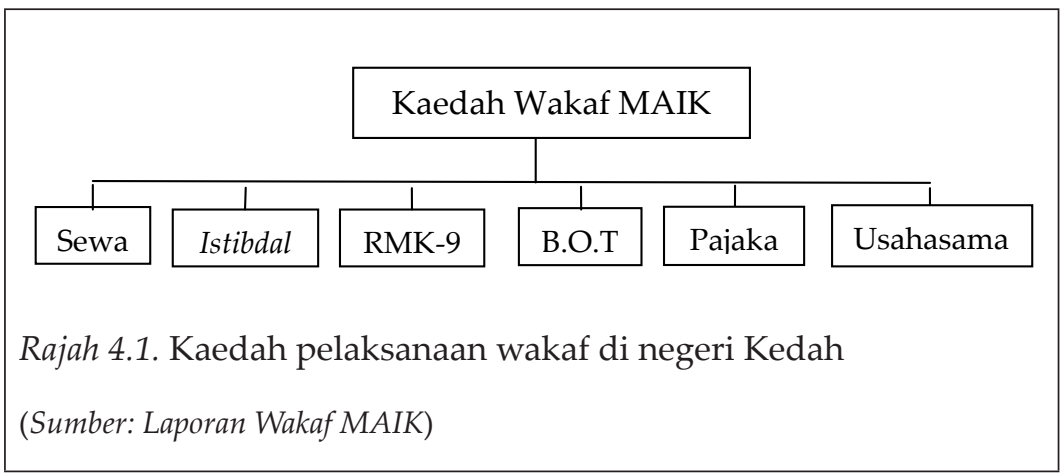

\section{Kaedah Sewa}

Kaedah sewaan harta wakaf telah dilaksanakan di antara MAIK dengan penyewa sama ada penyewa tersebut berupa syarikat atau individu tertentu. Penggunaan kaedah ini boleh dilihat terhadap sewaan sawah padi, bangunan dan pencawang telekomunikasi. Hasil temu bual yang dilakukan dengan Ketua Bahagian Wakaf dan penelitian terhadap sumber dokumen wakaf MAIK mendapati keluasan harta wakaf sawah padi MAIK yang disewa adalah sebanyak 127.77 relong. Manakala pendapatan melalui sewaan sawah padi yang telah berjaya dipungut adalah sebanyak RM386,956.00 setahun. Ini merupakan satu jumlah yang agak besar yang berjaya diperoleh MAIK sebagai pemegang amanah wakaf.

Kaedah sewaan sawah padi ini dilakukan secara akad sewaan harta wakaf untuk kegunaan pertanian serta tertakluk di bawah Akta Penanaman Padi (mengawal sewa dan menjamin pemegangan), 1967. Tempoh akad sewaan sawah wakaf MAIK untuk kegunaan pertanian telah diperuntukkan selama tiga tahun. Setelah tamat tempoh sewaan tersebut, penyewa akan diberi peluang untuk membuat permohonan memperbaharui akad sewaan tersebut. MAIK telah mengamalkan 
prinsip bertoleransi dalam sistem muamalatnya. Antara sistem muamalat MAIK yang cekap dan efisien adalah tidak menindas penyewa bahkan cara pembayaran mengikut kontrak dilakukan seperti, iaitu penyewa berjanji membayar sewa setiap musim dalam tempoh dua minggu selepas menuai.

Contoh sewaan harta wakaf yang seterusnya ialah penyewaan terhadap akad sewa bangunan MAIK seperti rumah kediaman dan juga lot komersial. Terdapat sedikit perbezaan di antara kaedah sewaan harta wakaf dan juga kaedah sewaan terhadap bangunan wakaf. Menurut MAIK perjanjian penyewaan bangunan lot komersial MAIK adalah selama tiga tahun, kemudian perjanjian penyewaan tersebut akan diperbaharui atas budi bicara. Sementara perjanjian penyewaan kepada penyewa baru perlu diperbaharui setiap tahun selama tiga tahun. Kadar sewaan untuk tahun pertama dan kedua adalah tidak berubah. Manakala kadar sewaan untuk tahun ketiga akan dinaikkan sebanyak $10 \%$ daripada kadar sewaan asal.

\section{Kaedah Istibdal}

Manual Pengurusan Tanah Wakaf (2009) menjelaskan kaedah istibdal ialah menukar ganti harta yang telah diwakafkan dengan harta yang lain yang lebih baik. Proses tukar ganti dilaksanakan sama ada melalui proses pertukaran, pembelian atau penjualan dengan menuruti hukum syarak agar matlamat dan manfaat harta wakaf itu dapat dikekalkan. Menurut Mohammed Noor (2013), pelaksanaan kaedah istibdal yang dilakukan oleh MAIK bertujuan memberi kemudahan umum. Di antara contoh-contoh pembangunan harta wakaf MAIK menggunakan kaedah istibdal adalah seperti pembinaan pusat membeli-belah (Aman Sentral) di atas tapak Madrasah Salihiah, pembesaran Lapangan Terbang Sultan Abdul Halim, dan pembinaan Landasan Berkembar Kereta Api Elektrik (Ipoh-Padang Besar).

Madrasah Salihiah Alor Setar telah dirobohkan untuk tujuan pembinaan pusat membeli-belah (Aman Sentral) dengan menggunakan kaedah wakaf istibdal (ganti). Melalui kaedah istibdal, bayaran pampasan yang diperoleh daripada pemaju bagi tapak projek pembinaan tersebut berjumlah RM1,040,918.46 dan bayaran pampasan ke atas bangunan surau yang telah dirobohkan adalah berjumlah RM401,000.00. Manakala jumlah keseluruhan adalah sebanyak RM1,441,918.46. Wang pampasan ini telah digunakan untuk menggantikan tapak asal ke tapak baru iaitu di atas: i) PT 1623, 
HSD 8022, Bandar Alor Setar, seluas 658.8684 meter persegi @ 7092 kaki persegi, dan ii) Lot 2409, GRN 183063, Bandar Alor Setar, seluas 227 meter persegi yang terletak di Jalan Lumpur, Alor Setar.

Mohammed Noor (2013) menjelaskan, pembesaran Lapangan Terbang Sultan Abdul Halim melibatkan pengambilan harta wakaf sebanyak tiga lot (Lot 35, Lot 783 dan Lot 121) yang berupa sawah padi. Lot pertama adalah Lot 35 GM 1002 mukim Titi Gajah, daerah Kota Setar. Lot ini merupakan wakaf khas di mana hasil yang diperoleh daripadanya akan disalurkan kepada Masjid Tuan Hussin Titi Gajah. Manakala Lot 783 H.S(M) 600/87 mukim Titi Gajah, daerah Kota Setar merupakan lot harta wakaf yang kedua. Pendapatan yang diperolehi melalui hasil pertanian tersebut diwakafkan khas ke Sekolah Menengah Agama Maktab Mahmud. Manakala lot terakhir adalah Lot 121 SP 8907 mukim Titi Gajah, daerah Kota Setar. Hasil yang diperoleh daripada lot ini diwakafkan khas kepada Masjid Bukit Pinang, daerah Kota Setar, Kedah.

Ketiga-tiga aset tersebut telah diambil oleh pihak kerajaan dengan bayaran pampasan sejumlah RM315,000.00. Dengan penerimaan pampasan tersebut, MAIK telah membeli satu lot bangunan kedai di Plot 16-H.S (M) 1634 PT 584, Taman Angsana, mukim Bandar Pokok Sena, daerah Pokok Sena sebagai ganti kepada harta wakaf yang telah diambil oleh pihak kerajaan. Hasil yang diperoleh melalui sewaan bangunan rumah kedai tersebut diagihkan kepada pihak yang sama, iaitu Sekolah Menengah Agama Maktab Mahmud dan Masjid Bukit Pinang seperti syarat yang telah ditentukan oleh pihak pewakaf. Dengan berbuat demikian pihak pemegang amanah harta wakaf MAIK telah menunaikan hasrat pewakaf agar ia diagihkan kepada saluran yang telah ditetapkan.

Seterusnya kaedah istibdal telah digunakan untuk tujuan projek pembinaan landasan berkembar kereta api elektrik (Ipoh-Padang Besar). Pembinaan landasan berkembar kereta api elektrik ini turut melibatkan pengambilan harta wakaf MAIK yang terletak di daerah Kota Setar. Di antara lot-lot harta wakaf yang terlibat adalah Lot 3 (keluasan 650 meter persegi) dan Lot 1219 (556 meter persegi), keduadua lot tersebut terletak di Kampung Tok Seron, daerah Kota Setar.

Di antara harta-harta wakaf lain yang terlibat dalam pembayaran pampasan adalah Lot 4 (831 meter persegi) dan Lot 5 (821 meter persegi). Kedua-dua lot tersebut terletak di Kampung Pegawai, daerah Kota Setar. Penggunaan asal harta wakaf berkenaan adalah kawasan perkuburan masyarakat Islam. 
Meskipun, harta wakaf berkenaan telah diambil oleh pihak kerajaan, namun pihak berkuasa telah membayar pampasan bagi kesemua harta tersebut berjumlah RM1,920,000.00. Hasil daripada pampasan tersebut pihak MAIK telah membeli ganti harta berkenaan dengan Lot 1220 (keluasan 0.2429 hektar) dan Lot 1221 (keluasan 0.5530 hektar) yang terletak di mukim Pengkalan Kundur, daerah Kota Setar.

\section{Kaedah Pembiayaan Rancangan Malaysia Ke-Sembilan (RMK-9)}

Pembangunan harta wakaf MAIK adalah melalui pembiayaan JAWHAR di bawah RMK-9. Pembangunan harta wakaf ini mendapat suntikan sebanyak RM2 juta untuk menyiapkan asrama anak-anak yatim yang terletak di Lot 1241 Lorong Seri, daerah Kota Setar, Alor Setar, Kedah.

Berdasarkan laporan yang diperoleh melalui Bahagian Wakaf, Ibu Pejabat Jabatan Kerja Raya Kuala Lumpur (JKR) telah menyerahkan projek pembinaan asrama anak-anak yatim kepada syarikat pemaju, iaitu Satria Kasturi Sdn Bhd bagi menyiapkan asrama berkenaan. Kerja bagi menyiapkan asrama anak-anak yatim ini telah bermula pada 15 September 2008 dan telah siap pada 06 Disember 2009. Manakala majlis penyerahan bangunan telah diadakan pada 9 Disember 2011. Penyerahan bangunan berkenaan oleh JKR kepada JAWHAR seterusnya diserahkan kepada MAIK. Bangunan asrama anak-anak yatim yang dinamakan sebagai Darul Aitam Wal Masakin Sultanah Haminah binti Hamidun telah dirasmikan oleh Ke Bawah Duli Yang Maha Mulia Tuanku Sultan Negeri Kedah.

\section{Kaedah Build, Operate, Transfer (B.O.T)}

Mat Noor dan Mohd Yunus (2011) menjelaskan bahawa kaedah B.O.T merupakan sebuah kontrak yang tidak bercanggah dengan prinsip syariah. Bahkan kaedah B.O.T telah dipraktikkan oleh kebanyakan negara-negara maju di dunia bagi membina dan membangunkan infrastruktur awam atau swasta. Sebahagian daripada pembangunan harta wakaf MAIK dengan menggunakan kaedah B.O.T adalah seperti pembangunan yang dilaksanakan di antara MAIK dan Baitulmal.

MAIK telah memajukan beberapa projek pembangunan tanah wakaf dengan Baitulmal dengan menggunakan kaedah B.O.T seperti pembinaan rumah kedai, 2 tingkat di Lot. 907, Mukim Baling 
bagi fasa 1 bermula 2 Mei 2001 dan siap pada 19 November 2002 dengan kos pembinaan sebanyak RM1,023,677.32. Manakala fasa 2 pembinaan telah bermula pada tarikh 1 Oktober dan siap pada 22 Jun 2003 dengan kos pembinaannya sebanyak RM888,888.00 (Laporan Pembangunan hartanah wakaf MAIK, 2015).

Menurut MAIK satu Jawatankuasa Pelaburan dan Pembangunan Tanah Wakaf yang ditubuhkan oleh MAIK dan Baitulmal negeri Kedah diberi tanggungjawab untuk merangka beberapa pelan pembangunan bersepadu bertujuan memaju harta-harta wakaf MAIK. Harta-harta wakaf yang terletak di lokasi yang strategik serta mempunyai nilai komersil akan dibangunkan dengan pelbagai projek seperti projek perumahan, kompleks perniagaan dan rumah kedai. Justeru, pihak MAIK mampu memungut hasil pendapatan harta wakaf sebanyak lima belas peratus (15\%). Hasil kutipan pendapatan tersebut akan diagihkan mengikut matlamat dan tujuan asal wakaf, iaitu untuk kemaslahatan agama dan umat Islam (Laporan Pembangunan hartanah wakaf MAIK, 2015).

Penggunaan kaedah B.O.T juga turut dilaksanakan di harta wakaf yang lain di Kedah seperti Lot 4492, 4493, 4494 dan 4495 . Kesemua lot tersebut berada di daerah Bandar Baharu. Jumlah keluasan keseluruhan harta berkenaan adalah sekitar 8,000 kaki persegi. Baitulmal telah memperuntukan sebanyak RM1.2 juta untuk membina bangunan kedai 2 tingkat. Hasil yang diperoleh daripada 3 lot kedai dipungut oleh Baitulmal sementara 1 lot lagi dipungut oleh masjid Bagan Samak, Kampung Chelong. Melalui kaedah B.O.T, Baitulmal akan menyerahkan kesemua harta bangunan berkenaan kepada MAIK setelah Baitulmal berjaya mendapatkan modalnya melalui hasil yang dijana daripada ketiga-tiga lot berkenaan.

\section{Kaedah Usahasama}

Kaedah usahasama merupakan salah satu aktiviti untuk menjalankan sesuatu perniagaan atau membangunkan sesuatu projek yang melibatkan persyarikatan dua pihak. Che Omar (2010) menjelaskan bahawa kadang-kala kaedah usahasama tidak perlu kepada penubuhan syarikat tetapi hanya melibatkan penjanaan idea, tenaga kepakaran serta modal. Hasil temu bual dengan Pengurus Pembangunan Perniagaan, Pemodalan Kedah Berhad (PKB) mendapati pembangunan harta wakaf yang telah dilaksanakan di antara MAIK dan PKB-Capital Sdn Bhd merupakan 
pemegang amanah projek pembangunan hartanah tanpa melibatkan penubuhan syarikat usahasama. MAIK sebagai pemilik berdaftar dan tanah wakaf telah bersetuju memberi pajakan tanah kepada pemaju mengikut terma-terma dan syarat seperti dinyatakan dalam perjanjian pajakan. Tanggungjawab PKB-Capital Sdn Bhd sebagai pemaju adalah untuk merancang dan membangunkan tanah, menanggung kos pembangunan projek, menyediakan kepakaran teknikal sehinggalah berurusan dengan pihak pembeli bagi penjualan unit-unit perumahan yang dibangunkan.

Projek Pembangunan harta wakaf MAIK yang dilaksanakan oleh PKB Capital Sdn. Bhd. terletak di Lot 227, Mergong, Daerah Kota Setar, Kedah Darul Aman. Tanah wakaf ini berada dalam kawasan pembangunan yang strategik kerana kedudukannya berdekatan zon perindustrian seperti kilang pembuatan tayar Continental, perindustrian kecil dan sederhana (IKS). Selain itu, keunikan kediaman tersebut adalah berdekatan dengan pasaraya seperti Tesco, Aman Sentral, Alor Setar Mall serta berada di laluan alternatif untuk ke Perlis serta laluan ke lebuhraya PLUS.

Kajian menunjukan, pembangunan harta wakaf MAIK adalah selari dengan tuntutan akidah dan syariat. Oleh itu, menjadi tanggungjawab kepada pemegang amanah agar mengemblingkan segala ilmu dan kepakaran untuk membangunkan harta wakaf agar menjadi harta yang produktif serta dapat memberikan sumbangan dan manfaatnya kepada umat Islam. Inilah maksud dan tujuan wakaf seperti yang ditegaskan oleh baginda Rasulullah SAW kepada Umar r.a.

\section{Kaedah Pajakan}

Pengerusi Jawatankuasa Fatwa MAIK Dato' Paduka Syeikh Abdul Majid bin Muhamad Noor yang bertarikh 27 Mei 1990 menyatakan tentang keharusan membangunkan tanah wakaf dengan menggunakan kaedah pajakan (al-Tahkir). Pajakan tidak bermaksud melupuskan hak milik Allah. Namun, kaedah pajakan adalah sebagai salah satu alternatif untuk tambah nilai terhadap harta wakaf bagi menjamin benifisiari serta manfaat dapat ditambahkan melalui hasil pajakan tersebut.

Berdasarkan keputusan majlis fatwa tersebut, maka MAIK telah merealisasikan kaedah pajakan 99 tahun antara pihak MAIK dengan Binaan Sentosa Sdn Bhd serta dengan beberapa pihak lain. MAIK 
telah menyerahkan tanah wakaf khas (anak cucu / zuriat) beralamat di Lot 871, Jalan Putra Bandar Alor Setar kepada Binaan Sentosa Sdn Bhd untuk membangunkan kompleks perniagaan yang dinamakan Plaza Putra. Melalui kaedah pajakan 99 tahun, pihak MAIK telah menerima pulangan sebanyak RM4,000,000.00.

Justeru terdapat juga beberapa pandangan fuqaha' yang menerangkan tentang tempoh maksimun dan minimum dalam merealisasikan kaedah pajakan terhadap harta wakaf. Para fuqaha' berbeza pendapat tentang tempoh pajakan wakaf sama ada perlu dinyatakan secara khusus atau umum. Para fuqaha' berselisih pendapat tentang tempoh pajakan yang panjang seperti kajian al-Masri (2009). Antara perbezaan pandangan dalam kalangan para fuqaha' berkaitan dengan tempoh pajakan yang panjang adalah seperti berikut:

i. Pajakan secara mutlak tanpa menyebutkan had tempoh masa secara khusus, dan

ii. tempoh tertentu yang disyorkan oleh para fuqaha'.

Para fuqaha' juga turut berbeza pandangan tentang tempoh pajakan secara mutlak tanpa menyebutkan tempoh masa secara khusus. Kajian terhadap kitab-kitab figh menjelaskan isu pajakan tanpa had masa ini membawa kepada dua pandangan yang berbeza.

Pandangan pertama adalah jumhur fuqaha's yang terdiri daripada mazhab al-Malikiyah, al-Syafi'iyyah, al-Hanabilah dan sebahagian daripada pandangan ulamak al-Hanafiyah yang berpandangan bahawa pajakan secara mutlak tanpa menyebutkan had masa secara khusus adalah tidak diharuskan. Bahkan, sistem pajakan secara mutlak ini akan mengundang kemudaratan kepada pemilik wakaf dan akan berlaku pelupusan hak wakaf secara tidak langsung.

Pandangan kedua berpendapat harus pajakan wakaf secara mutlak tanpa menyebutkan had tempoh masa secara khusus meskipun tempoh pajakan itu panjang. Ini adalah pandangan sebahagian daripada fuqaha' terdahulu dan terkemudian dalam mazhab alHanafiyah. Pandangan inilah yang mengharuskan kaedah al-ahkar ${ }^{9}$.

Kajian mendapati pandangan jumhur fuqaha' adalah lebih rajih dan lebih mesra dilaksanakan kerana terdapat kawalan dan pemantauan terhadap harta wakaf. Bahkan kaedah pajakan dengan menyebutkan

8 al-Dirdir (1996), al-Shirbini (1996), Ibn Qayyim al-Jauziyah (1996) Abu Bakar alTarablusi (1993).

9 Ibid Kahf (2000). 
tempoh masa secara khusus, pengurus akan lebih prihatin memastikan agar tanah wakaf berada di dalam terjamin dan terurus.

Kesemua kaedah pembangunan harta wakaf yang telah diamalkan oleh Majlis Agama Islam Negeri Kedah (MAIK) mempunyai kebaikan yang tersendiri. Antara kebaikan kaedah pembangunan harta wakaf yang telah dilaksanakan oleh MAIK, Pertama ia boleh dijadikan sebagai aliran tunai untuk memulakan sesebuah pembangunan di atas tanah wakaf itu tersendiri. Masalah aliran tunai dilihat amat kritikal dalam usaha membangunkan sesebuah tanah wakaf di Malaysia kerana kebanyakan harta wakaf di Malaysia berupa aset kekal seperti tanah, bangunan, masjid dan lain lain. Kedua, asetaset tersebut akan terselamat daripada kerosakan. Ini kerana apabila berlaku kerosakan ia dapat diselenggara dengan kadar segera. Justeru kos untuk penambahbaikan dapat dikurangkan. Ketiga, dapatan pulangan untuk setiap pembangunan yang dilaksanakan sama ada dalam bentuk sewaan mahupun terciptanya aset yang baharu. Justeru, pihak pengurusan harta wakaf tidak perlu mencari sumber kewangan lain untuk tujuan pengurusan aset wakaf itu sendiri.

\section{Kesimpulan}

Pengurusan terhadap sumber kewangan Islam masih lagi berada ditahap yang kritikal. Ini dapat dilihat dengan masih terdapat banyak lagi tanah-tanah wakaf di Malaysia tidak dioptimunkan penggunaannya. Hal ini terjadi disebabkan beberapa faktor seperti kurangnya tenaga mahir untuk tujuan tersebut, kekurangan dana modal untuk tujuan membuat pengolahan terhadap tanah wakaf dan lain lain lagi. Di Kedah, MAIK telah mengorak langkah yang berani dalam merealisasikan usaha tersebut. Ini dapat dilihat dengan beberapa kejayaan pembangunan harta wakaf telah diukir seperti pembinaan kompleks perniagaan Plaza Putra di Alor Setar. MAIK menggunakan kaedah pajakan tanah untuk tempoh 99 tahun (kerjasama MAIK dengan Binaan Sentosa Sdn Bhd). Di samping itu juga, pihak MAIK telah menerima pulangan sebanyak RM4,000,000.00 untuk tujuan tersebut.

\section{Rujukan}

Abu Bakar al-Tarablusi, B.I. (1993). al-Is'af fi Ahkam al-Awqaf, Cetakan Dar al-Tiba'ah al-Kubra, Kaherah. 
Abu Zahrah, M, (2009). Muhadarat fi al-Waqf, Cetakan Dar al-Fikr al-Arabi, Kaherah.

Che Omar, A. R. (2010). Harta Wakaf dan Keusahawanan: Suatu Analisis, Jurnal Pengurusan JAWHAR, 43-59.

Al-Dirdir, A. A. (1996), Sharh al-Saghir 'ala Akrab al-Masalik ila Mazhab al-Imam al-Malik, Cetakan Dar al-Kutub al-Ilmiah, Beirut.

Fatwa MAIK Dato' Paduka Syeikh Abdul Majid bin Muhamad Noor, al-Tahkir, (27 Mei 1990)

Hashim, H., \& Ab. Rahman, A. (2013), Pengurusan Pembangunan Harta Wakaf Secara komersil yang Dilaksanakan Majlis Agama Islam Wilayah persekutuan Kuala Lumpur (MAIWPKL), Jurnal Pengurusan JAWHAR, 119-135.

(2015), Pembiayaan Pembangunan Harta Wakaf Menggunakan Sukuk, Cetakan Pertama, UM Press, Kuala Lumpur, Malaysia.

Ibn Abidin, M.A. (2011), Radd al-Mukhtar 'ala al-Durr al-Mukhtar Syarh al-Abshor, Cetakan Dar al-Kutub al-Ilmiah, Beirut.

Ibn Qayyim al-Jauziyah, M (1996) I'lam al-Muwaqqi' in 'An Rabb alAlamin, Cetakan Dar al-Kutub al-Ilmiyyah, Beirut.

Kahf, M. (1998), Financing the Development of Awqaf Propety, Paper Prepared for Seminar on Development of Awqaf Organized by IRTI, Kuala Lumpur, 1- 45.

Kahf, M. (2000), al-Waqfal-Islami Tatawwuruhu, Iradatuhu, Tanmiyyatuhu, Cetakan Dar al Fikr, Beirut.

Laporan Pembangunan Hartanah Wakaf MAIK, 2015.

Mohammed Noor, A. (2013), Kesan-kesan Pelaksanaan Istibdal Wakaf di Negeri Kedah Darul Aman, Jurnal Muamalat JAKIM, 59-77.

Mat Noor, A., \& Mohd Yunus, S. (2011), Penggunaan Akad ‘Build, Operate and Transfer' Sebagai Cara Pembiayaan (Kewangan) Untuk Membangun Tanah Wakaf: Satu Analisis Projek Pembangunan Wakaf oleh Majlis Agama Islam Wilayah Persekutuan Kuala Lumpur, Jurnal Muamalat, JAKIM, 1-30.

Manual Pengurusan Wakaf (2009) JAWHAR, Jabatan Perdana Menteri.

al-Masri, Y (2009), al-Awqaf Fiqhan wa Iqtisadan, Cetakan Dar alMaktabi, Damsyik.

al-Mimmi, H. (1998), Ahlu al-Zimmah fi al-Hadarah al-Islamiyyah, Cetakan Dar al-Gharb a al-Islamiah, Beirut.

al-Shirbini, M.A. (1995), Mugni al-Muhtaj, Cetakan Dar al-Fikr, Kaherah. Umar, M (2003), Qadaya Iqtisadiyyah Muasirah min Manzur Islami, Silsilah al-Halaqah al Niqashiyyah, Al-Azhar University, 77-100. al-Zarqa, M. A. (1999), al-Madkhal ila Nazariyyah al-Iltizam al-Ammah fi al-Figh al-Islami, Dar al-Qalam, Beirut. 